\title{
Rice Transplanting Mechanization in Bangladesh: Way to Make It Sustainable
}

\author{
Md. Anwar Hossen*, Md. Mahir Shahriyar, Sharmin Islam, Haimonti Paul, Md. Mizanur Rahman \\ Farm Machinery and Post-Harvest Technology Division, Bangladesh Rice Research Institute (BRRI), Gazipur, Bangladesh \\ Email: *ahossenbrri@gmail.com
}

How to cite this paper: Hossen, M.A., Shahriyar, M.M., Islam, S., Paul, H. and Rahman, M.M. (2022) Rice Transplanting Mechanization in Bangladesh: Way to Make It Sustainable. Agricultural Sciences, 13, 130-149.

https://doi.org/10.4236/as.2022.132011

Received: January 5, 2022

Accepted: February 7, 2022

Published: February 10, 2022

Copyright $\odot 2022$ by author(s) and Scientific Research Publishing Inc. This work is licensed under the Creative Commons Attribution International License (CC BY 4.0).

http://creativecommons.org/licenses/by/4.0/

(c) (i) Open Access

\begin{abstract}
"Rice transplanter" has brought a radical change in the method of rice seedlings transplanting in Bangladesh. The machine is gaining popularity with the increase of labor crisis during the peak period of transplanting, reduction time of in-between crops, rapid urbanization and industrialization, and changing socio-economic status of the farmers. Alternatively, the traditional way of rice transplanting is labor-intensive and involves high drudgery. Mechanical rice transplanter is cost-effective and operation-friendly. It is suitable to plant young seedlings maintaining plant to plant and line to line distance which plays an important role in increasing yield. Moreover, it is easy to take care of the crops planted in rows. It helps in maintaining soil physical properties and is considered to be better from a crop management and productivity point of view. In malignancy of having an edge over the traditional broadcasting, the adoption rate of mechanical transplanters is low due to high primary investment, lack of knowledge in growing mat type nursery, lack of repair and maintenance facility to the end-users, and unavailability of spare parts. Imparting these, available supply, entrepreneurship development, and encouraging custom hire services may be some of the practical results for adding the rice area under mechanical transplanting. This review summarizes the problems and prospects associated with seedling rice transplanting, technological gaps in the adoption of mechanical transplanters in a sustainable manner, and future ways to make transplanters more user-friendly and cost-effective.
\end{abstract}

\section{Keywords}

Rice Establishment, Transplanter, Mechanization, Mat Type Seedling, Operator Training

\section{Introduction}

The term "rice is life" is most relevant in Bangladesh as the rice stands for the 
first crop in the agriculture and its economy as it is grown in about 11.77 million ha (Aus: 1.134 ha, Aman: 5.88 ha, and Boro: 4.75 ha) producing 38.70 million tons of rough rice (Aus: 3.012 ton, Aman: 15.50 ton and Boro: 20.18 ton) with average productivity of 3.18 ton/ha [1]. Rice plays a significant role in the country's food security and is the support of sustenance for millions of rural people [2]. Wetland transplanting in puddled conditions and direct seeding of rice are the two basic methods of rice establishment [3] [4]. Wetland transplanting in puddle conditions is a more famous method of rice establishment in Asia as well as in Bangladesh because of better return and less weed infestation when contrasted with direct seeding of rice. The advantages of transplanting in puddled conditions include increased nutrient availability (e.g. iron, zinc, phosphorous) and weed suppression. Puddling is a process of tillage to mix the soil and water by which a hardpan is created below the plow zone to reduce soil permeability under conventional planting [5]. Notwithstanding, it requires high energy, a huge amount of irrigation water, and furthermore, it is work escalated [6] [7]. Puddle transplanting of rice seedlings is either done physically or mechanically. Manual wash root rice seedling transplanting in puddle fields is a very common and popular practice of rice establishment among Bangladeshi farmers. Manual transplanting in the puddled field is time-consuming and tedious which required more labor when contrasted with mechanical transplanting.

It was discovered execution of the mechanical transplanter was passable with a work prerequisite of 3 man-days for each hectare against 33 man-days for every hectare if there should be an occurrence of manual transplanting [8]. In another study, it was observed that manual paddy transplanting needed around 238 man hours for every hectare [9]. The actual field capacity of the six rows manually operated paddy transplanter was 0.38 ha each day while for hand transplanting it was 0.04 ha each day [10]. The rate of area coverage of the rice transplanter also varied with season. Mixed fertilizer deep placement technology was incorporated in the walking type rice transplanter (ARP-4UM) to place fertilizers into the soil and found the rate of average area coverage of several trials in Boro and Aman season 0.12 and $0.23 \mathrm{ha} / \mathrm{h}$ respectively while it was $0.13 \mathrm{ha} / \mathrm{h}$ and $0.26 \mathrm{ha} / \mathrm{h}$ without fertilizer deep placement mechanism [11] [12]. However, riding-type rice transplanter achieved more field capacity compared to walking-type rice transplanter while manual transplanting rate is much less [13]. The field capacity of the riding type rice transplanter was found $0.2380 \mathrm{ha} / \mathrm{h}$ which is significantly superior to manual transplanting and walking transplanter, which achieved a capacity stood 0.0038 and $0.1370 \mathrm{ha} / \mathrm{h}$ respectively [14]. Moreover, mechanical transplanting gave higher yield advantages compared to manual transplanting using walking (DP480) type and riding (S3-680) type rice transplanter resulted in the higher productive tiller as well as higher grains $/ \mathrm{m}^{2}$. Average yield advantages in Aman and Boro seasons of 60 trials in different locations of Bangladesh were found 0.12 and $0.35 \mathrm{t} / \mathrm{ha}$ respectively [13]. The result of various rice establishment techniques was assessed and the most extreme grain efficiency (54.8 
$\mathrm{q} \cdot \mathrm{ha}^{-1}$ ) was found under the arrangement of rice intensification method followed by mechanical transplanter (49.8 $\left.\mathrm{q} \cdot \mathrm{ha}^{-1}\right)$, planting a sprouted seed with SRI marker $\left(45.2 \mathrm{q} \cdot \mathrm{ha}^{-1}\right)$, line transplanting $\left(44.9 \mathrm{q} \cdot \mathrm{ha}^{-1}\right)$, manual transplanting (39.6 $\left.\mathrm{q} \cdot \mathrm{ha}^{-1}\right)$ and least productivity of grain (39.50 $\left.\mathrm{q} \cdot \mathrm{ha}^{-1}\right)$ was observed if there should arise an occurrence of planting by pregerminated paddy seeder [15].

A four rows manually operated rice transplanter using root-washed seedlings created by the National Institute of Agricultural Engineering, U.K. was first tried at C.R.R.I., Cuttack in 1966. The rice seedling transplanting effectiveness was $70 \%-80 \%$ and the work prerequisite was $220-245 \mathrm{man}-\mathrm{h} / \mathrm{ha}$ [16]. In Bangladesh, mechanical transplanters were developed at the Institutional level and are now under popularizing among the ranchers. Though, most of the farmers used imported rice transplanters. The crisis of manpower during the peak transplanting period and increasing rice transplanter is forcing the policymakers to make changes in outlook toward the upgraded utilization of mechanical activity in rice cultivating. This review works examine the problems associated with different rice transplanting methods, critical technological gaps in adoption of mechanical transplanters and suggests future research policy to make transplanter more users friendly.

\section{Common Methods of Rice Transplanting}

\subsection{Traditional Transplanting}

Manual transplanting in the puddled field by hand is still mostly practiced in Bangladesh. For manual transplanting, a person has to uproot seedling from seedbed and wash for binding and carrying to the main field which is laborious and time-consuming. In addition, a person has to work in the puddled field and bend for a long time for seedling transplanting into the soil which is also extremely labor-intensive, tedious, and wearisome. For manual transplanting (nursery raising, uprooting of the seedling, and transplanting) more than 300 worker hours are needed for 1 hectare of land [17]. Manual transplanting of rice seedlings includes the uprooting of 30 - 45 days old seedling and transplanting them (4 - 10 seedlings per hill) in a well puddled and leveled field. Manual transplantation of rice is labor-intensive work and is directly linked to human suffering. The majority of respondents (20 samples) of a study carried out in Kalinagar village of U.S. Nagar, District of Uttarakhand state in 2011 experienced neck pain in their shoulders, upper back, lower back, and thighs during manual uprooting and transplantation [18]. Musculoskeletal disorder is a common problem for long time work in bending mode. Only walking in puddled fields burned through $72 \%$ to $87 \%$ of the complete energy expense of male laborers while for female laborers it ranged from $83 \%$ to $89 \%$ for traditional transplanting [19]. An ergonomic investigation on human drudgery and musculoskeletal issues shows that manual rice transplanting, requesting high labor and straightforwardly connected with human drudgery (torment in neck, both shoulder, upper back, 
lower back, and thighs) on the grounds that the works were constrained to embrace twisting and sitting stance during manual seedling uprooting and transplanting [20]. An examination of more than 344 Thai rice ranchers matured between 20 - 59 years shows the commonness of low back pain in $83.1 \%$ of ranchers [21] [22]. One of the plausible choices to take care of the issue would be the selection of mechanical transplanting.

\subsection{Mechanical Transplanting Using Manually Operated Rice Transplanter}

A manual transplanter is a helpful machine for smallholder farmers because of its low cost, minimum repair, and maintenance cost, and higher field capacity when contrasted with hand transplanting. Major components of a manually operated rice transplanter are floats, a mainframe assembly made of MS pipe that supported the seeding tray made of G.I. sheet, pushing lever tray indexing mechanism, assemble of pickers in a bar and two handles for seedling pushing and machine carrying in backward motion of the operators (Figure 1).
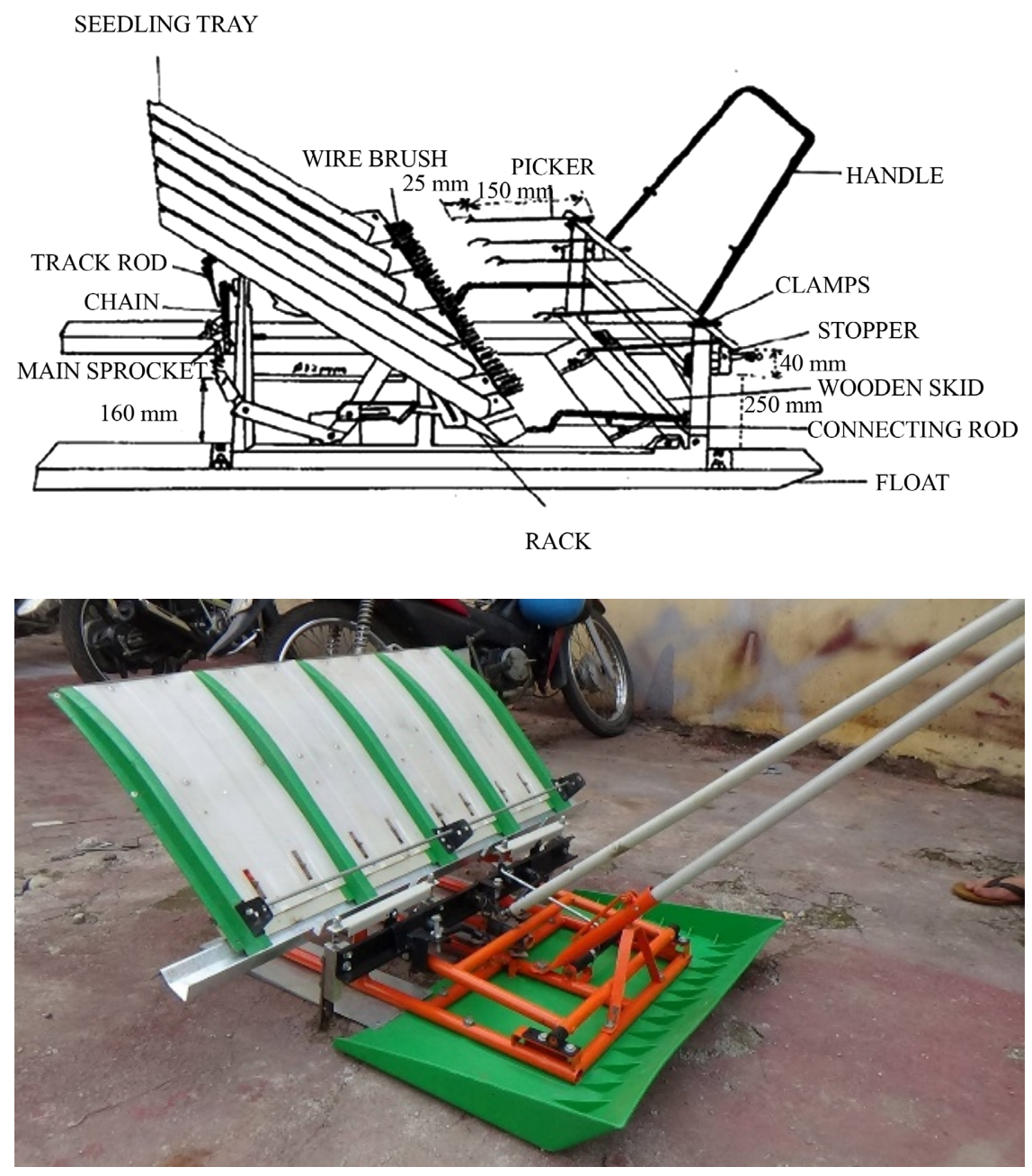

Figure 1. Field operation of the BRRI developed manual rice transplanter. 
One operator can operate the transplanter in the puddled field having minimum water in backward motion by push and pull action. Multitask activities are involved in the operation of the manual rice transplanter. The machine has to move in reverse, pull the machine in one hand, and at the same time push the handle to cut the nursery and plant into the soil. The field conditions ought to be ideal for better execution of transplanter. Manual rice transplanter can be used for timely transplanting with minimum labor and less cost of rice seedling transplanting. The average energy expenditures of male and female workers in the transplantation process using a manual rice transplanter were found to be 30.70 and $32.58 \mathrm{~kJ} \cdot \mathrm{min}^{-1}$, respectively. On the other hand, the average force required to pull the transplanter was found in male and female subjects 130.32 and $145.12 \mathrm{~N}$ respectively [10].

In Bangladesh, Syedul et al. (2000) first worked on manually operated rice transplanter for the improvement of the IRRI-designed, 6-row manually-operated rice transplanter and developed a 5-row prototype replacing the wooden made skid by G.I. sheet which made it more durable, lightweight, and incurred less sliding resistance [23]. At full load, the IRRI and BRRI planters weighed $37 \mathrm{~kg}$ and $30 \mathrm{~kg}$, respectively. The dragging force of the BRRI transplanter was reduced by $25 \%$ - $30 \%$ compared with the IRRI transplanter while the circular configuration of the picker finger of the IRRI transplanter was changed to a semi-circular one, which increase its cutting action. The actual field capacities for the BRRI rice transplanter, IRRI rice transplanter, and hand transplanting were 0.0191 $\mathrm{ha} / \mathrm{h}, 0.0155 \mathrm{ha} / \mathrm{h}$, and $0.0023 \mathrm{ha} / \mathrm{h}$, respectively. Therefore, machine transplanting with traditional nursery seedlings methods was found more profitable compared to the hand transplanting method. Even then, there was involved a high force of seedling cutting action and drudgery of operation in the muddy field in a backward motion. Farm Machinery and Postharvest Technology (FMPHT) Division of Bangladesh Rice Research Institute (BRRI) took an initiative to improve the technology under a government subsidy program in 2008. The field capacity of the developed rice transplanter was $0.05 \mathrm{ha} \cdot \mathrm{h}^{-1}$. Compare with manual transplanting, the machine can save about $60 \%$ labor and $45 \%$ transplanting cost [24]. Modified transplanter was performed well in the field but there was a problem of backward motion in operation. BRRI again took a program to develop a forward motion type manually operated rice transplanter [25].

However, working in the muddy field and simultaneously pushing and pulling activities at the same time to the manual transplanter is a complex task that required more endeavors of the operators. A similar result was found in Punjab Agricultural University, Ludhiana of 6 rows manual transplanter which is having a rate of area coverage of $0.03-0.035 \mathrm{ha} \cdot \mathrm{h}^{-1}$ and required $57-66 \mathrm{man}-\mathrm{h} / \mathrm{ha}$ and that was 2 - 3 times less than the conventional practices [26]. Even, manually operated six rows paddy transplanter ergonomically opined as "hefty work" based on pulse and recommended rest delay of $14.30 \mathrm{~min}$ followed by $30 \mathrm{~min}$ of work for completing useful transplanting operation [10]. Considering the drudgery of 
the four and six rows manually operated rice transplanter, Selvan et al., 2014 built up a three rows improved force type transplanter by resolving the push-pull activities during transplanting [27]. The rate of area coverage was $0.058 \mathrm{ha} \cdot \mathrm{h}^{-1}$ along with minimum missing hills when the total draft was $261.7 \mathrm{~N}$. The amount of energy for transplanting decreased by $24.8 \%$ which significantly decrease the drudgery.

\subsection{Mechanical Transplanting Using Power-Operated Rice Transplanter}

Considering the present labor crisis during the whole period in farm operations, the government trying to advance mechanization, on the whole, the conceivable ways to make rice production profitable. The farmers have come forward to receive the advanced rice transplanting technology with the help of self-propelled rice transplanters. Because of small landholding and weak economic position, farmers are not in a situation to buy the machine separately, yet on a hiring basis, the technology ought to be received. The mechanical transplanters are classified on the basis of nursery used i.e., machine using wash root seedling and machine using mat type seedlings [28]. Ministry of Agriculture, Bangladesh started a new concept of synchronized rice seedling transplanting to avoid the problems of farm road and smallholding problems [29]. It is still under the research level. Mat type rice seedling raising technique is a little bit complex and farmers are not habituated to follow the proper management that significantly affects the machine performance. About $40 \%$ of the total energy is required for mat-type rice seedling raising in mechanical transplanting while energy share for conventional nurseries under manual transplanting is only $11 \%$ [30]. Mat-type seedlings are raised either on a plastic tray or on a polythene sheet with the assistance of a casing or frame. Either dry soil or clay soil is used in tray preparation. Normally 15 - 20 days old seedlings in Aman (Non-irrigated and hot season) season and 25 - 30 days old seedling Boro (Irrigated and cold season) season were found most suitable for mechanical transplanting [31]. Mat thickness for best result should be maintained $2.0-2.5 \mathrm{~cm}$ irrespective of season, variety, and growing media. Mechanical transplanting using mat-type rice seedling is becoming more popular because of its high precision of transplanting, high capacity, and reduced labor requirement of $50 \mathrm{man}-\mathrm{h} / \mathrm{ha}$ [32]. Mechanical transplanting has an economic benefit over traditional rice seedling transplanting. Power operated rice transplanter gave the net benefit of Rs 1146.00 and Rs 1319.00 per ha when yearly utilization of machine was $300 \mathrm{~h}$ (one season) and $500 \mathrm{~h}$ (two seasons), individually, over the manual transplanting and the recompense time frame for investment on the transplanter was 10.23 years and 1 year when yearly area covered was 20 and 80 ha, separately [33].

The mechanical transplanting altogether increased grain yield around 23\%, $37 \%$, and $63 \%$, straw yield around $17 \%, 14 \%$ and $22 \%$, and natural yield around $20 \%, 24 \%$, and $39 \%$ over manual transplanting, dry direct seeding, and direct 
seeding of sprouted rice in puddled conditions, separately [34]. Grain yield increased with the self-propelled walk-behind type (9.3\%) and self-propelled four-wheel type (6.7\%) transplanters over manual practice [35].

Walking type 8 row transplanter was not available in Bangladesh but 6 rows are now importing some companies which are under evaluation. The scenario of adoption of self-impelled paddy transplanting technology among paddy cultivators of Bangladesh is still low, which calls for improved innovation and upgraded extension services for promoting the self-propelled paddy transplanting innovation. The transplanter with the incorporation of deep placement of fertilizer applicator is one of the conceivable adjustments that should have been presented. The important role of urea has great potential in most small-scale rice farmers in Asia, where farmers are generally deprived of resources [36]. From this point of view, BRRI modified the walk-behind type rice transplanter by incorporating fertilizer deep placement mechanism under NATP-2 funded project [12]. This is under the adoption stage. There is a need to promote self-propelled walking type rice transplanters for small and medium land holdings rice. It is necessary to promote a power operated walk-behind type rice transplanter for small and medium-sized rice farmers. The walking and riding type rice transplanter (Figure 2) might be presented on enormous size land hanging on a custom employing premise.
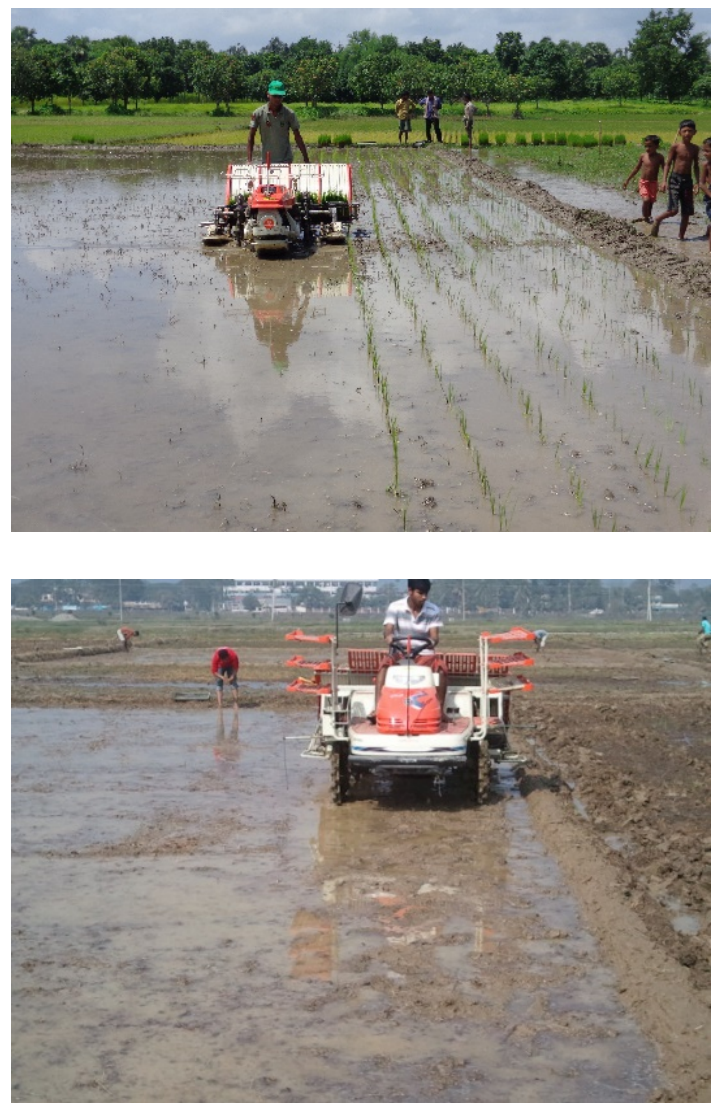

Figure 2. Field operation of the walk behind type and riding type rice transplanter. 


\section{Precision Transplanter}

In Bangladesh, the number of precision rice transplanters at the farmers' level is increasing rapidly. The government subsidy program under the DAE (Department of Agricultural Extension) is enhancing the popularity of the mechanical rice transplanter. Difficulties of mat type seedling raising and unavailability of skilled operators during the peak period of transplanting are the major reason for the slow adoption of the machine. To minimize the labor involved in seedling raising and transplanting, quick adopting of precision rice transplanter is needed under the continuous support of the subsidy program. Parallel, training programs over the country should be continued for developing skilled operators. Some popular model of rice transplanter was selected under the subsidy program for adoption at the farmers' level (Table 1).

It is necessary to evaluate the subsided machine performance after a few years to identify the right machine for Bangladesh condition considering farmers socio-economic condition, land size, prices, service of the machine, operation and repair-maintenances facility, service life, etc. Uneven fields, land size, soil conditions are the major factors that influence the performance of rice transplanters. If necessary, there is a need to modify the available rice transplanter that can work efficiently on Bangladesh conditions. Liguo et al., 2014 developed an automatic navigation system on PZ60 rice transplanter based on global navigation

Table 1. Different model of rice transplanter selected by the national technical committee under subsidy project of DAE.

\begin{tabular}{|c|c|c|c|c|c|c|c|}
\hline $\begin{array}{l}\text { Sl. } \\
\text { No. }\end{array}$ & Type & Brand \& Model & $\begin{array}{l}\text { Country } \\
\text { of origin }\end{array}$ & $\begin{array}{c}\text { Engine } \\
\text { power }(\mathrm{HP})\end{array}$ & $\begin{array}{c}\text { No. } \\
\text { of rows }\end{array}$ & $\begin{array}{c}\text { Theoretical } \\
\text { transplanting speed } \\
(\mathrm{m} / \mathrm{s})\end{array}$ & $\begin{array}{c}\text { Effective field } \\
\text { capacity } \\
\text { (ha/h) }\end{array}$ \\
\hline 1. & Walking & Kubota (SPW-48C) & Japan & 3.5 & 4 & $0.34-0.77$ & 0.18 \\
\hline 2. & Walking & Mahindra (MP461) & India & 3.9 & 4 & $0-0.83$ & 0.18 \\
\hline 3. & Walking & Janata (2ZS-4C) & China & 4.5 & 4 & $0.34-0.77$ & 0.15 \\
\hline 4. & Walking & Daedong (DP488) & Korea & 4.0 & 4 & $0.4-0.75$ & 0.13 \\
\hline 5. & Riding & Daedong (ERP60D) & Korea & 22 & 6 & $0-1.7$ & 0.43 \\
\hline 6. & Walking & FMWORLD (2ZS-6B) & China & 5.0 & 6 & $0.28-0.8$ & 0.12 \\
\hline 7. & Riding & FMWORLD (2ZGF-6A) & China & 20 & 6 & $0-1.62$ & 0.46 \\
\hline 8. & Walking & UTTARON (2ZS-630S) & China & 5.0 & 6 & $0.26-0.8$ & 0.18 \\
\hline 9. & Walking & FLW (2ZF-4K) & China & 4.0 & 4 & $0.28-0.78$ & 0.30 \\
\hline 10. & Riding & FLW (2ZG-6DK) & China & 20.8 & 6 & $0-1.65$ & 0.19 \\
\hline 11. & Walking & CYMATRO (2ZS-4C) & China & 3.5 & 4 & $1.0-2.77$ & 0.12 \\
\hline 12. & Walking & Yanmar (AP4) & Japan & 3.5 & 4 & 0.38 to 0.76 & 0.20 \\
\hline 13. & Riding & Yanmar (YR70D) & Japan & 20.9 & 7 & 1.65 & 0.32 \\
\hline 14. & Walking & WUBOTA (2ZX-6) & China & 4.5 & 6 & $0.28-0.77$ & 0.12 \\
\hline
\end{tabular}

Source: Department of Agricultural Extension (DAE), 2022. 
satellite system (GNSS) considering the problems of variable soil conditions, hard work environment, the driver driving level, and the long boring driving to follow line is a big influence to the accuracy of the rice transplant [37]. S. Lin et al. 2020 developed an automatic detection of plant rows for a transplanter in a paddy field using a faster R-CNN algorithm to serve as a navigation system of a rice transplanter for maintaining uniform plant row spacing in a paddy field which is a critical requirement for rice seedling transplanting, as it affects subsequent field management and the crop yield [38]. Aggregate hierarchical clustering (AHC) was used to group rice seedlings into rows of seedlings and use them to determine navigation parameters. For the precise operation of an autonomous rice transplanter guided by a global positioning system, an inertial measurement unit was developed [39].

\section{Present Challenges of Mechanical Rice Transplanting}

Mechanized transplanting technology is an all-around systemic technology combined with agricultural machinery and agronomic technique. Mechanization helps increase harvest intensity by reducing lead times and speeding agricultural activities. There are various challenges in mechanized transplanting in Bangladesh which describe as follows:

\subsection{Size, Shape and Fragmented Land}

The operation efficiency of machines generally becomes higher in proportion to the size of field plots and the length width (L/W) ratio of plots [40]. The present land ownership system in Bangladesh does not allow the movement of farm machinery from plots to plots. Besides, the land size of the country is mostly small, fragmented, and irregular in shape. The small size land restricts operating larger size farm machinery. The fragmented land increased the plot to plot movement time. The daily area coverage of the transplanter depended on the plot to plot distance, plot size, seedlings tray supply, and the number of plots under transplanting activity [41]. Smaller plots were not favorable to operate transplanter and did not possess economic feasibility. Small plots having less than $250 \mathrm{~m}^{2}$ is not suitable to operate a 4-row walking type transplanter [42]. In addition, field sizes less than $400 \mathrm{~m}^{2}$ should be avoided to get the good performance of a 6-row riding type transplanter [41]. Therefore, in order to promote the national agricultural mechanization, the expansion of land area is an urgent issue.

\subsection{Lack of Knowledge and Skill}

The operators (farmers and custom-hire service providers) of agricultural machinery and equipment are mostly unaware of the operation and maintenance schedule of their machines and equipment. The manufacturing sub-sector is lacking skilled and experienced workforce almost in all levels of manufacturing, repair \& maintenance, and management of businesses [43] [44]. Even then, proper knowledge is important to get the maximum benefit of mechanized rice 
transplanting. Most of the rice transplanter owner is suffering due to a lack of technical manpower [45]. However, BRRI, DAE, BAU, and the different nongovernment organizations provide training considering the importance of mechanization. Farmers Training should provide both technical knowledge and business skills in a convenient location, and at a convenient time. The operators must know the strategy of transplanting seedlings in the headland. The operators should know the approach of driving the machine efficiently in the plots surrounded by crops on its two or three sides. The transplanting machine should operate at walking speed. Sudden turns should be avoided to prevent accidents. In order to benefit, operators need access to information and training which is tailored to their needs.

\subsection{Appropriate Design \& Development}

Bangladesh imports many types of Agricultural Machinery. Prices of this machinery are very high. In many cases, it is beyond the capacity to purchase of poor farmers [46]. The premature release of machines for economic procedure leads to many field problems and serious farmers' dissatisfaction [47]. Development of the market for local products is very slow. However, after-sales service and repair maintenance facilities are very poor. In most of the remote rural areas of the country, there is a scarcity of quality spare parts, replaceable tools, and accessories of agricultural machines in spare parts shops of local hat and bazaars [43]. In recent times, due to price hikes of imported pigiron and shipbreaking scrap the foundries are mostly relying on local irons crap, as a result, it becomes hard to maintain the quality of products especially the hardness of finished products [43]. BRRI is working to develop a suitable rice transplanter considering the socio-economic conditions of the country.

\subsection{Mat Type Seeding Raising}

The success of rice transplanter depends on the seedling quality. For mechanical transplanting, like conventional method, nursery is not raised in plots or fields. Uniform seedling density is essential for mechanical rice transplanting system. Optimal rice sowing rate is also important if a uniform stand is established with a sufficient number of plants [48]. Seedling should be raised with special care, suitable seedling age, materials and advanced practices including tray and nursery bed soil, seed preparation for pre-germination and disease disinfection. Because raising seedling is the key step for mechanical transplanting. Nursery raising is labour intensive and cumbersome job because special levelled place, soil preparation and regular irrigation by sprinkling are needed. Nurseries are labor-intensive because it requires special leveled areas, soil preparation, and regular irrigation by watering. Raising nursery for a very large paddy area is very costly. On the other sides, the soil above the agricultural land is usually used for sowing seeds in trays. Therefore, the height of agricultural land will reduce to normal level. Hossen et al., 2020 conducted a research and found suitable to 
raise mat type seedling using cow-dung, rice bran, rice husk and tea wastage at the rate of $5 \%-15 \%$ [49]. However, seedling quality varied among the organic fertilizers in the order of cow-dung $>$ rice bran $>$ vermicompost $>$ poultry liter $>$ rice straw organic fertilizer $>$ mustard cake. Clay loam soil had better rolling quality than sandy loam soil [50]. Based on missing hills and number of seedlings hill, $140 \mathrm{~g}$ of seeds/tray for short and bold grain, $130 \mathrm{~g}$ of seeds/tray for medium and slender grain and $120 \mathrm{~g}$ of seeds/tray for extra-long and slender paddy found suitable to get optimum seedlings per hill and minimize missing hills [50]. During Boro season, seedling raising is difficult due to biotic and abiotic stress in cold weather. Tamanna et al. 2021 found that $0.08 \mathrm{~mm}$ thick white polythene as a covering mechanism and $\mathrm{MoP}$ as a treating mechanism for seedling rising in cold weather [51].

\subsection{Field Condition}

Land condition is important to ensure that the rice field is ready for planting. The performance of mechanical rice transplanter mainly depends on the field condition at the time of transplanting. It is pre-requisite to prepare the land properly for mechanical rice transplanting. For final preparation, field should be puddled three to four times to a depth of $5-7 \mathrm{~cm}$. The puddling also maximizes breaking of capillaries and minimizes seepage and percolation of water. A well-prepared land helps to control weeds, recycles plant nutrients and provides a suitable soil surface for transplanting. Puddled fields should be leveled and the soil allowed to settle for 12 - 48 hours based on soil type for avoiding soil flow for better seedling establishment [52] [53] [54] [55]. A well puddled and leveled field helps in maintaining $3-4 \mathrm{~cm}$ standing water for easy and smooth operation of mechanical transplanter [54]. Joseph stated that it should maintain a uniform depth of $1-2 \mathrm{~cm}$ standing water during planting [52]. Size and shape of the land has a significant effect on the operational efficiency of mechanical rice transplanter. Land having irregular shape and small in size caused extra travel, caused low transplanting capacity and high cost. When the size of plots is small, turning events and mobility depended on the length of the plot, plots having larger lengths substantially reduced the loss of time due to extra turning travel, hence increased the field capacity of the mechanical rice transplanter [42].

\section{The Way of Overcoming the Challenges of Mechanical Rice Transplanting in Bangladesh}

\subsection{Seedling Raising Technique}

Seedlings are one of the key controllers for successful operation of Rice Transplanter. For mechanical transplanting with transplanter need special seed bed [32]. A lot of work has been done in this regard in BRRI and other organization and it is still going on. Seedlings preparation in tray requires skill and knowledge which should be provided to the farmers. Now the need is to reach the farmer level and get adequate training on proper seedling raising. Moreover, synchro- 
nized cultivation in Bangladesh has been started and should be made popular over the country involving research organization. This is another major obstacle as the top soil of the land is used for making mat type seedlings. Different growing media also can be used to avoid top soil used in tray preparation. Research has been done using different mediums for growing mat type seedling. Hossen et al. 2020 suggested that $10 \%$ to $15 \%$ of cow-dung or rice bran mixture with both sandy loam and clay loam soil was found suitable as growing media to get quality seedling in mat for mechanical transplanting [49]. This problem can be solved by establishing entrepreneurs at the farmer level. This requires coordination at the government and private levels. Coordination can be done by providing area based responsibilities of the different government, non-government organization and machine suppliers. Proper hands on training facilities should be given to the farmers about seedling raising technique. Rice transplanter will be successful in the field if the seedling raising technology can be spread among the farmers properly.

\subsection{Land Size and Shape}

Plot size, shape, farm roads, and soil bearing capacity significantly influence the machine performance in the field during operation. The daily area coverage of the transplanter depended on the plot to plot distance, plot size, seedlings tray supply, and the number of plots under transplanting activity [41]. Small and fragmented field (less than $250 \mathrm{~m}^{2}$ ) is not suitable to operate a 4-row walking type transplanter [42] while field sizes less than $400 \mathrm{~m}^{2}$ should be avoided to get the good performance of a 6-row riding type transplanter [41]. The plot L/W ratio has a great influence on the performance of farm machinery. The total number of turns depended on the L/W ratio of the plots and transplanting path (length or width-wise). Length-wise operation of farm machinery is preferable to minimize the turning events. Plot length should be increased by keeping the same plot size. The operation efficiency of machines generally becomes higher in proportion to the size of field plots and the $\mathrm{L} / \mathrm{W}$ ratio of plots [40]. The efficiency of the transplanter increased with the increase in the L/W ratio. Land improvement works by consolidating the smaller plots may not be possible at this stage due to the socio-economic condition of farmers. However, entrepreneurs may follow the operational consolidation (plot shape, size, and plot to plot distance) while operating the transplanter machine in the field. The importance of operational consolidation can also get the maximum daily area coverage of the farm machine [41] and [56]. Synchronized cultivation that has been started in Bangladesh needs to extend to avail the problems of fragmented land of the farmers [29]. Manual transplanting influenced in the pocket areas of the field where movement of mechanical rice transplanter is problems due to smaller size and irregular shape of plots. Those plots should be enlarged and reshaped to ensure the accessibility of transplanter machines under synchronized cultivation. Land improvement work is suggested to facilitate the accessibility of the farm machine 
into the field by creating farm road and to improve the better performance of the farm machine [42].

\subsection{Increase Knowledge and Skill}

Mechanical transplanter is one of the sophisticated and knowledge based technology in rice production which is hampering the popularity of the machine at the farmers' level. Right persons should be selected to provide rice transplanter's operation, repair and maintenance training in the key locations of the country. Proper knowledge is required for the owners and the operators about calibration of the machine in terms of soil condition, soil type, seedling height, seedling density, actual seedling spacing, and the number of seedlings dispensed in each stroke [57]. Agricultural engineers with technical knowledge should be recruited to monitor and advise the transplanting activities at every upazilla level [57] [58]. The effective linkage should be established among farmers (rice transplanter users), operators, extension workers, and researchers for enhancing mechanization.

\subsection{Appropriate Design \& Development}

The design and manufacturing of agricultural machinery are very intricate and sometimes universal design could not be enough as some machinery performance depends on local agricultural input features [59]. Soil condition and location-specific rice transplanter should be designed and developed. The private sector with the help of the government can play an important role in mechanization by manufacturing tools or machine parts rather than importing these from other countries with a high payment of tax. If the companies start to manufacture the machinery parts, then they can sell the machinery at a low price. Proper repair and maintenance facilities of rice transplanters need to be developed in every upazilla through agricultural extension services [57]. Sales and service centers for modern agro-machinery should be developed in each of the Upazila's of every district to enhance mechanization sustainability.

\section{Role of Research and Extension Linkage for Mechanized Transplanting and Future Trust}

Mechanical rice transplanting is the most vital issue and gaining familiarity to overcome labor shortage and high wage of labor during transplanting. Rice transplanting machines are quite recently introduced in Bangladesh. Around $0.1 \%$ of rice fields are mechanically transplanted and need interference to popularize [60]. Coverage of mechanical transplanting is increasing in Bangladesh [45] [61]. Mechanical rice transplanting has been treated as time and labor savings, transplanting in proper time and maintaining optimum plant density that helps to high productivity [62]. But, the high price of the machine, lack of seedling raising technique, availability of the machine, lack of knowledge, shortage of properly trained operators, and unavailability of spares parts make the rice 
transplanter awkward to farmers. However, the dissemination of rice transplanter could be pushed by the continuation of the research program, training on seedling raising technique, training on machine operation, repair, and maintenance as well as the public partnership approach of rice transplanter at farmer's field [62]. Recently, the ministry of agriculture has taken steps to formulate mechanization Roadmap 2021, 2031, and 2041 leading the basic and applied research to develop modern machinery like rice transplanter [63]. Research and development are the essential steps to formulate and implement rice transplanters in different regions of Bangladesh. Mechanical rice transplanter is considered one of the most sophisticated machines compared to other agricultural types of machinery. A collaborative research approach may help to overcome the complexity of rice transplanter [58]. Different universities and research organizations should conduct their research as individually or the same machinery is being developed by various organizations. This type of research will be motivated the researcher to conduct an integrated approach. To enhance the research potential of machinery, a proper production process like modern foundry, heat treatment services need to establish an agricultural machinery lab at different research organizations and Universities. Higher training facilities are predominant to develop the research capacity of the researcher [63]. However, collaborative research among the foreign delegates, research institutes, agriculture extension organizations, local manufacturing industries, and marketing entrepreneurs is important to develop and disseminate agricultural machinery.

Department of Agriculture Extension is playing a vital role in the faster transformation of rice transplanter technology at the farmer's field level. At present, DAE provided around 300 rice transplanters through a government subsidy program at the rate of $70 \%$ in haor and $50 \%$ in southern regions of Bangladesh [64]. Adaptive trial and field demonstration of mechanical rice transplanting are suitable techniques to create awareness among the farmers. The BRRI, BAU, GBK, BRAC, IRRI, BADC, and private organizations were arranged several field demonstrations to introduce the transplanter performance, price, operation technique, repair, and maintenance at farmers' fields level. This type of field works has significantly changed the mind of farmers and encouraged them to use rice transplanters [65]. Field day and crop cut programs are another technique to create awareness and quicker dissemination of rice transplanter. Field day helps to share the benefits of utilizing the rice transplanter where the crop cut program showed the yields advantage of mechanically transplanted rice compared to traditional transplanting. However, a skilled workforce needs to include to the extent these types of training and demonstrations. DAE has inadequate professional manpower and needs to establish the agricultural engineering wing by recruitment of agricultural engineers [57]. The agricultural agencies or private organizations may provide the loan facilities to purchase the rice transplanter of farmers. These organizations may also provide the custom hire service facility to farmers to use rice transplanter and its dissemination across Bangladesh. 


\section{Conclusion}

Mechanical rice transplanters are one of the possible options for dealing with farm labor shortages. However, popularization has been delayed due to the tedious process of growing rice seedlings on trays and mats, which has not been properly addressed by stakeholders. Providing appropriate on-the-job training to stakeholders regarding nursery preparation procedures and planting machine handling will increase the adoption rate of currently available rice transplanter machines. Effective linkage among the governmental organization, nongovernmental organization, and machinery importers need to formulate on a realistic basis. Inexpensive and ease of operation type rice transplanter need to be designed for Bangladesh conditions.

\section{Conflicts of Interest}

The authors declare no conflicts of interest regarding the publication of this paper.

\section{References}

[1] BRRI (2021) Rice Database: Rice Area, Production and Yield in Bangladesh 2019-2020. http://brri.gov.bd

[2] Ghulam Hussain, S. (2012) Chapter 5. Role of Rice in Food Security of Bangladesh. In: Food Security: Quality Management, Issues and Economic Implications, Nova Publishers, Hauppauge, 127-148.

[3] Kumar, A., Nayak, A.K., Mohanty, S. and Das, B.S. (2016) Greenhouse Gas Emission from Direct Seeded Paddy Fields under Different Soil Water Potentials in Eastern India. Agriculture, Ecosystems \& Environment, 228, 111-123. https://doi.org/10.1016/j.agee.2016.05.007

[4] Kumar, A., Nayak, A.K., Pani, D.R. and Das, B.S. (2017) Physiological and Morphological Responses of Four Different Rice Cultivars to Soil Water Potential Based Deficit Irrigation Management Strategies. Field Crops Research, 205, 78-94. https://doi.org/10.1016/j.fcr.2017.01.026

[5] Dawe, D., Barker, R. and Secler, D. (1998) Water Supply and Demand for Food Security in Asia. The Workshop on Increasing Water Productivity and Efficiency of Rice Based Irrigation Systems, Los Banos, 29-31 July 1998, 212-220.

[6] Hossain, M.A. and Siddique, M.N.A. (2015) Water-A Limiting Resource for Sustainable Agriculture in Bangladesh. EC Agriculture, 1, 124-137.

[7] Verma, A. (2010) Modelling for Mechanization Strategies of Rice Cultivation in Chhattisgarh, India. Agricultural Mechanization in Asia, Africa and Latin America, $41,20$.

[8] Manjunatha, M.V., Reddy, B.G.M., Shashidhar, S.D. and Joshi, V.R. (2009) Studies on the Performance of Self-Propelled Rice Transplanter and Its Effect on Crop Yield. Karnataka Journal of Agricultural Sciences, 22, 385-387.

[9] Dixit, J. and Khan, J.N. (2011) Comparative Field Evaluation of Self-Propelled Paddy Transplanter with Hand Transplanting in Valley Lands of Kashmir Region. Agricultural Mechanization in Asia, Africa and Latin America, 42, 14-18.

[10] Yadav, R., Mital, P., Shukla, S.P. and Pund, S. (2007) Ergonomic Evaluation of Ma- 
nually Operated Six-Row Paddy Transplanter. International Agricultural Engineering Journal, 16, 147-157.

https://www.researchgate.net/publication/264042841_Ergonomic evaluation of m anually operated six-row paddy transplanter

[11] Hossen, M.A., Kamruzzam, M., Islam, M.M., Rahman, M.A. and Kabir, M.S. (2019) Fertilizers Application Simultaneously with Mechanical Rice Transplanting in Bangladesh. Agricultural Engineering International: CIGR Journal, 21, 64-74. https://www.researchgate.net/publication/341985319 Fertilizers application simult aneously with mechanical rice transplanting in Bangladesh

[12] Hossen, M.A., Bhuiyan, M.G.K., Rahman, M.M., Zaman, M.K., Islam, M.M. and Rahman, M.A. (2020) Development of Mixed Fertilizer Deep Placement Technology into Soil Simultaneously with Mechanical Rice Seedling Transplanting. Journal of Science, Technology and Environment Informatics, 9, 649-644. https://doi.org/10.18801/jstei.090220.66

[13] Hossen, M.A., Huda, M.D., Zaman, M.K., Islam, M.M. and Aktar, S. (2018) Validation of Walking and Riding Type Rice Transplanter in Different Location of Bangladesh. Journal of Eco-Friendly Agriculture, 11, 43-59.

https://www.researchgate.net/publication/333198893 Validation of walking and $\mathbf{r}$ iding type rice transplanter in different location of Bangladesh

[14] Alzubaidi, A.A.J., Ahmad, A.S. and Galley, A.A. (2016) The Effect of Transplanting Methods on Field Capacity and Two Rice Cultivars Yield. Elixir Agriculture, 95, 40772-40775.

https://www.elixirpublishers.com/articles/1465038998 95\%20(2016)\%2040772-4077 5.pdf

[15] Mohanty, D.K., Barik, K.C. and Behera, D. (2014) Comparative Performance of Different Rice Establishment Methods for Sustainable Rice Production in Deogarh District of Odisha. Agricultural Engineering Today, 38, 5-9.

[16] Das, F.C. (2009) Report on Status and Prospects of Mechanisation in Rice. Rice Knowledge Management Portal. 1-24.

[17] Hossen M.A. (2021a) Final Workshop on Design and Development of Fertilizer Deep Placement Mechanism for Existing Rice Transplanter Welcome. Completion Workshop of the NATP-2 Funded Project (ID-064) Entitle Design and Development of Fertilizer Deep Placement Mechanism for Existing Rice Transplanter (ID-064).

[18] Ojha, P. and Kwatra, S. (2012) An Ergonomic Study on Human Drudgery and Musculoskeletal Disorders by Rice Transplanting. Studies on Home and Community Science, 6, 15-20. https://doi.org/10.1080/09737189.2012.11885351

[19] Karunanithi, R. and Tajuddin, A. (2003) Physiological Response of Agricultural Workers in Rice Farming Operations. Journal of Agricultural Engineering, 40, 33-40.

[20] Park, W. and Kim, S. (2005) Mechanizing Paddy Rice Cultivation in Korea. Rice Is Life: Scientific Perspectives for the 21st Century. Proceedings of the World Rice Research Conference, Tokyo and Tsukuba, 4-7 November 2005, 226.

[21] Keawduangdee, P., Puntumetakul, R., Swangnetr, M., Laohasiriwong, W., Settheetham, D., Yamauchi, J. and Boucaut, R. (2015) Prevalence of Low Back Pain and Associated Factors among Farmers during the Rice Transplanting Process. The Journal of Physical Therapy Science, 27, 2239-2245. https://doi.org/10.1589/jpts.27.2239

[22] Taechasubamorn, P., Nopkesorn, T. and Pannarunothai, S. (2011) Prevalence of Low Back Pain among Rice Farmers in a Rural Community in Thailand. Journal of 
the Medical Association of Thailand, 94, 616-621.

https://citeseerx.ist.psu.edu/viewdoc/download?doi=10.1.1.467.9953\&rep=rep1\&typ $\underline{e}=\mathrm{pdf}$

[23] Islam, M.S., Ahmad, D. and Baqui, M.A. (2000) Modification, Test and Evaluation of Manually-Operated Transplanters for Lowland Paddy. Ama, Agricultural Mechanization in Asia, Africa \& Latin America, 31, 33-38.

https://www.researchgate.net/publication/282723925 Modification test and evalu ation of manually-operated transplanters for lowland paddy

[24] Huda, M.D., Milan, M.K., Bhuiyan, M.G.K., Paul, S., Islam, S., Islam, M.M. and Rahman, M.A. (2016) Design and Development of Manual Rice Transplanter. The Annual Research Review Workshop of Bangladesh Rice Research Institute (BRRI) under Farm Machinery and Post Harvest Technology Division, Gazipur, 12-17 January 2016, 6-10.

[25] Hossen, M.A. and Rahman, M.A. (2020) Development of a Forward Motion Manual Rice Transplanter. The Annual Research Review Workshop of Bangladesh Rice Research Institute (BRRI) under Farm Machinery and Post harvest Technology Division, Gazipur, 15-20 February 2020, 12-15.

[26] Singh, S. and Vatsa, D.K. (2006) Performance Evaluation of PAU Manual Paddy Transplanterin Hills of Himachal Pradesh. Agricultural Engineering Today, 30, 19-25.

[27] Selvan, M.M., Annamalai, S.J.K., Thavaprakash, N. and Ananathakrishnan, D. (2014) Design and Development of Three-Row Improved Pull-Type Rice Transplanter for Small Farmers. The Indian Journal of Agricultural Sciences, 84, 130-135.

[28] Guru, P.K., Chhuneja, N.K., Dixit, A., Tiwari, P. and Kumar, A. (2018) Mechanical Transplanting of Rice in India: Status, Technological Gaps and Future Thrust. ORYZA-An International Journal on Rice Oryza, 55, 100-106. https://doi.org/10.5958/2249-5266.2018.00012.7

[29] Hossen, M.A. (2021) A Popular Article on "Synchronized Cultivation-A Science Based Method”. Daily Bartoman Somoi, 02 January, 2022.

https://www.researchgate.net/publication/350132378 samalaya casa-ekati bijnana bhittika pad'dhati Synchronized cultivation - A science based method

[30] Baruah, D.C., Goswami, N.G. and Saikia, R. (2001) Manual Transplanting vs. Mechanical Transplanting of Paddy: A Techno-Economic Analysis in Assam. Journal of Agricultural Engineering, 38, 66-72.

[31] Hossen, M.A., Bhuiyan, M.G.K., Islam, M.M. and Rahman, M.A. (2020) Rice Transplamter Cum Mixed Fertilizer Applicator. Publication Number 301, Bangladesh Rice Research Institute, Gazipur.

https://www.researchgate.net/publication/357510589 Manual of Rice transplanter cum mixed fertilizer applicator

[32] Dixit, A., Khurana, R., Singh, J. and Singh, G. (2007) Comparative Performance of Different Paddy Transplanters Developed in India-A Review. Agricultural Reviews, 28, 262-269.

[33] Chaudhary, V.P., Varshney, B.P. and Kalra, M.S. (2005) Self-Propelled Rice Transplanter-A Better Alternative than Manual Transplanting. Agricultural Engineering Today, 29, 32-37.

[34] Singh, K.K., Lohan, S.K., Jat, A.S. and Rani, T. (2006) New Technologies for Planting Rice for Higher Production. Research on Crops, 7, 369-371.

[35] Manes, G.S., Dixit, A., Singh, A., Mahal, J.S. and Mahajan, G. (2013) Feasibility of 
Mechanical Transplanter for Paddy Transplanting in Punjab. Agricultural Mechanization in Asia, Africa and Latin America, 44, 14-17.

[36] Bautista, E.U., Koike, M. and Suministrado, D.C. (2001b) Mechanical Deep Placement of Nitrogen in Wetland Rice. Journal of Agricultural Engineering Research, 78, 333-346. https://doi.org/10.1006/jaer.2000.0675

[37] Wei, L.G., Zhang, X.C., Jia, Q. and Liu, Y.C. (2014) Automatic Navigation System Research for PZ60 Rice Planter. 8th International Conference on Computer and Computing Technologies in Agriculture (CCTA), Beijing, September 2014, 653-661. https://doi.org/10.1007/978-3-319-19620-6 73

[38] Lin, S.M., et al. (2020) Automatic Detection of Plant Rows for a Transplanter in Paddy Field Using Faster R-CNN. IEEE Access, 8, 147231-147240.

https://creativecommons.org/licenses/by/4.0 https://doi.org/10.1109/ACCESS.2020.3015891

[39] Nagasaka, Y., Saito, H., Tamaki, K., Seki, M., Kobayashi, K. and Taniwaki, K. (2009) An Autonomous Rice Transplanter Guided by Global Positioning System and Inertial Measurement Unit. Journal of Field Robotics, 26, 537-548.

https://doi.org/10.1002/rob.20294

[40] Taniyama, S. (1975) Land Consolidation in Paddy Fields. In: Symposium on Water Management in Rice Fields, Ministry of Agriculture and Forestry, Tokyo.

[41] Islam, A.K.M.S., Islam, M.T., Rabbani, M.A., Rahman, M.A. and Rahman, A.B.M.Z. (2015) Commercial Mechanical Rice Transplanting under Public Private Partnership in Bangladesh. Journal of Bioscience and Agriculture Research, 6, 501-511. https://doi.org/10.18801/jbar.060115.60

[42] Islam, A.K.M.S., Kabir, M.S. and Hossain, M.I. (2017) Present Land Size with Shape and Effect on the Operational Efficiency of Rice Transplanter. Journal of Science, Technology\& Environment Informatics, 5, 402-412. https://doi.org/10.18801/jstei.050217.43

[43] Alam, M. and Khan, I.N. (2017) Agricultural Mechanization: Status, Challenges and Opportunities in Bangladesh. In: Gurung, T.R., Kabir, W. and Bokhtiar, S.M., Eds., 2017. Mechanization for Sustainable Agricultural Intensification in SAARC Region, SAARC Agriculture Centre, Dhaka, 41-70.

[44] Islam, A.K.M.S. (2018) Status of Rice Farming Mechanization in Bangladesh. Journal of Bioscience and Agriculture Research, 17, 1386-1395. https://doi.org/10.18801/jbar.170118.171

[45] Hossen, M.A. (2020) A Popular Article on "Rice Transplanter: Provable Problems and Solutions at the Field Level”. Agrilife, 14 August 2020.

http://agrilife24.com/2020/2018-03-19-12-26-20/4060-anwar-14aug.html?fbclid=Iw AR2FaLMy7hvsss0Plg4n7MVbnu3kWXsfo08DJoEknke-SawnnY6p3UuMeLE

[46] Ahmed, R. (1984) Agricultural Price Policies under Complex Socioeconomic and Natural Constraints. The Case of Bangladesh. Bangladesh Agricultural Research Council, Dhaka, 15.

[47] Khalequzzaman, K.M. and Karim, M.A. (2007) Study of Agricultural Mechanization and Its Impact on Rural Environment. Journal of Innovation and Development Strategy, 1, 37-40.

[48] Runsick, S. and Wilson, C.E. (2009) Agriculture and Natural Resources. University of Arkansas Division of Agriculture. FSA2157-PD-5-09Na.

[49] Hossen, M.A., Shahed, A.B.M., A.l. Mamun M.R., Tamanna, T.A. amd Rahman, M.M. (2020) Effect of Mat Type Rice Seedling Growing Media on Block Formation 
and Fungal Infection. Journal of Bangladesh Agricultural University, 18, 1073-1082. https://doi.org/10.5455/JBAU.127431

[50] Hossen, M.A., Hossain, M.M., Hawue, M.E. and Bell, R.W. (2018) Effect of Growing Media on Mat Type Seedling Raised for Mechanical Rice Transplanting. Research in Agricultural Engineering, 64, 157-167. https://doi.org/10.17221/79/2016-RAE

[51] Tamanna, T.A., Hossen, M.A., Al Mamun M.R. and Shahed, A.B.M. (2021) Mitigation of Biotic and Abiotic Stresses in Mat Type Seedlings Raised for Mechanical Rice Transplanter. American Journal of Pure and Applied Biosciences, 3, 125-134. https://doi.org/10.34104/ajpab.021.01250134

[52] Joseph, F.R., Frank Mussgnug, C.M.K., Swetapadma, D.S., Nabakishore, P., Kapil, S., Vivek, K., Narayan, C.B., WasimIftikar, A.M., Sudhir, Y., Virender, K., Malik, R.K. and McDonald, A.J. (2015) A Manual on "Operational Manual for Mechanical Transplanting of Rice”. Cereal Systems Initiative for South Asia Phase II (CSISA). https://csisa.org/wp-content/uploads/sites/2/2014/06/Operational-Manual-for-Mec hanical-Transplanting-of-Rice.pdf

[53] Paul, S., Hossen, M.A., Nath, B.C., Rahman, M.A. and Hosen, S. (2016) Effect of Soil Settling Period on Performance of Rice Transplanter. International Journal of Sustainable Agricultural Technology, 12, 14-20. https://www.gscience.net https://www.researchgate.net/publication/332670477 EFFECT OF SOIL SETTLI NG PERIOD ON PERFORMANCE OF RICE TRANSPLANTER\#fullTextFileCo $\underline{\text { ntent }}$

[54] Shahid, M., Nayak, A.K., Tripathi, R., Sangita Mohanty, Panda, B.B., Saha, S., Vijayakumar, S., Mohapatra, S.D., Priyadarsini, S., Guru, P.K., Munda, S., Sarangi, D.R., Nagothu, U.S. and Pathak, H. (2019) Mechanical Transplanting of Rice. National Rice Research Institute (ICAR). http://resilienceindia.org/sites/default/files/3\%20Mechanical\%20Transplanting.pdf

[55] Al-Mamun, M.R., Islam, M.A., Lucky, A.K. and Hossen, M.A. (2020) Identification of Puddling Settling Period of Various Soil Textures for Mechanical Rice Transplanting. Agricultural Engineering International: CIGR Journal, 22, 40-47. https://www.researchgate.net/publication/347934946 Identification of puddling s ettling period of various soil textures for mechanical rice transplanting

[56] Mandal, M.A.S. (2017) Growth of Mechanisation in Bangladesh Agriculture: Role of Policies and Missing Links. In: Sattar Mandal, M.A., Biggs, S.D. and Justice, S.E., Eds., Rural Mechanization (A Driver in Agricultural Change and Rural Development), Institute for Inclusive Finance and Development (InM), PKSF Bhaban, Agargaon, Dhaka, 77-96.

[57] Rahman, M.M., Ali, M.R., Oliver, M.M.H., Hanif, M.A., Uddin, M.Z., Tamim-UlHasan, Saha, K.K., Islam, M.H. and Moniruzzaman, M. (2021) Farm Mechanization in Bangladesh: A Review of the Status, Roles, Policy, and Potentials. Journal of Agriculture and Food Research, 6, Article ID: 100225. https://doi.org/10.1016/j.jafr.2021.100225

[58] Hossen, M.A. (2020c) A Popular Article on "Agricultural Engineers and Sustainable Mechanization Are the Future of Agriculture". The Popular Daily Newspaper "Prothom Alo" Dated 12 February, 2020.

[59] Ali, M.R., Rahman, A., Kabir, M.S.N., Rahman, M.M., Mamun, M.R.A. and Hossen, M.A. (2020) Agricultural Mechanization in Bangladesh: Status and Challenges towards Achieving the Sustainable Development Goals (SDGs). Agricultural Mechanization in Asia, Africa and Latin America, 51, 106. 
[60] Alam, M. (2019) Study to Find Out Extent and Constraints of Use of Farm Machineries Developed by National Institutes of Bangladesh to Accelerate Mechanization. Final Report.

[61] Hossen M.A., Talukder, M.R.A., Mamun, M.R.A., Rahaman, H., Paul, S., Rahman, M.M., Miaruddin, M., Ali, M.A. and Islam, M.N. (2020) Mechanization Status, Promotional Activities and Government Strategies of Thailand and Vietnam in Comparison to Bangladesh. AgriEngineering, 2, 489-510.

https://doi.org/10.3390/agriengineering2040033

[62] Islam, A.S. (2016) Mechanized Rice Transplanting in Bangladesh. Bangladesh Rice Research Institute, Gazipur.

[63] Agriculture, M. (2020) National Agricultural Mechanization Policy 2020 (Issue October).

[64] Alam, M.M., Ashik-E-Rabbani, M., Begum, S., Sarkar, S., Basir, M.S. and Jones, M. (2019) Gender Technology Assessment under the Project Entitled "Appropriate Scale Mechanization Consortium”. An Online Publication.

https://agrilinks.org/sites/default/files/resources/bangladesh transplanter tech prof ile 201908 final.pdf

[65] Islam, A.K.M.S., Rahman, M.S., Das, S.R., Saha, T.K., Rahman, M.R., Islam, M.T. and Rabbani, M.A. (2017) Entrepreneurial Opportunity of Mechanical Rice Transplanting Service for Small Holder Farmer in Bangladesh. Progressive Agriculture, 28, 230-239. https://doi.org/10.3329/pa.v28i3.34660 